\title{
Conflict-induced Poverty: Evidence from Colombia ${ }^{1}$
}

\author{
Natalia Lemus Valencia
}

June 23, 2013

Thesis advisor: Juan Fernando Vargas

\begin{abstract}
The study of the relationship between conflict and poverty is very relevant in a country like Colombia, suffering one of the longest internal conflicts still present in the world today and being the second country in South America with the highest percentage of people below the poverty line. This study uses government deterrence measures as instruments of several conflict-specific variables to estimate the impact of conflict on poverty in Colombia. Using census-level data at the municipality level for 2005, I assess the effect on both the urban and rural incidence of the newly developed Multidimensional Poverty Index. The findings show that the incidence of conflict significantly increases rural poverty. This is consistent with the fact that most of the conflict in Colombia takes place in rural areas. I also explore the lagged effect of conflict on poverty to conclude that it lasts for at least three years, but decreases over time. Finally, I show that the results are robust to a battery of additional specifications, including the use of alternative conflict data and a modified version of the dependent variable.
\end{abstract}

\footnotetext{
1 Master thesis, Department of Economics, Universidad del Rosario. I am especially grateful to Juan Fernando Vargas for his excellent supervision. I thank Adriana Camacho, Manuel Ramirez, Roberto Angulo and Renata Pardo for their comments and suggestions that helped improved this thesis significantly. I also thank Catherine Rodríguez for sharing the database of government deterrence measures.
} 


\section{Introduction}

Poverty and conflict are closely related. Violent conflicts have led to high numbers of deaths and displaced people, material destruction and even state collapse. In most of the world, conflict has long lasting effects that inhibit economic development. ${ }^{2}$ The opposite argument is however also true: Poor people have a lower opportunity cost of engaging in illegal or violent activities and this may fuel conflict and crime (Becker, 1968). Hence, economic decline and poverty may reinforce tendencies to resort to violent means. Indeed, many researchers have observed that poverty and conflict go hand in hand, and have found that there is a strong negative relationship between GDP per capita and violent conflict across countries (Fearon and Laitin, 2003; and Collier and Hoeffler, 2004).

Given the usual identification concerns pertaining to the potential reverse causality between conflict and poverty, or the presence of omitted variables, it is difficult to identify the impact of conflict on poverty. Nevertheless, the aim of this study is to estimate this impact for the case of Colombia. In particular, using the Multidimensional Poverty Index (MPI) at the municipality level, I study the effect of conflict on poverty distinguishing between its urban and its rural incidence. Of course, as mentioned before, there are endogeneity challenges that I resolve instrumenting conflict with the number of illegal drug laboratories dismantled and the number of weapons seized, all of which are government deterrence measures. These instruments should be highly correlated with armed conflict given that they proxy for both the presence and effectiveness of the government to counteract criminal activity in the region. However, these measures are unlikely to affect poverty directly. This is the basic identification strategy of this study, and will be explained in more detail.

The government deterrence measures have already been used in other studies of the consequences of armed conflict in Colombia. For instance, Camacho and Rodríguez (2011) instrument conflict with illegal drug laboratories dismantled and antinarcotic operations, to estimate the causal effect that armed conflict has on entrepreneurial activity in Colombia. Moreover, Rodríguez and Sánchez (2012) estimate the effect of armed conflict exposure on school drop-out and labor decisions of Colombian children, by instrumenting conflict with the number of captures of assassins.

\footnotetext{
${ }^{2}$ See World Bank (2003) for a review.
} 
The question of the causal effect of conflict on poverty in a country like Colombia is very relevant, since the country suffers one of the longest internal conflicts still present in the world today and is the second country in South America with the highest percentage of people below the poverty line (World Bank, 2008).

Colombia has experienced civil conflict for about five decades. In the early sixties two guerrilla organizations emerged, respectively known as the Revolutionary Armed Forces of Colombia (FARC) and the National Liberation Army (ELN), both based on communist ideas. In addition, in the early eighties right-wing paramilitary groups emerged, and in 1997 they formed an umbrella organization known as the United Self-Defense Forces of Colombia (AUC). Although AUC demobilized between 2003 and 2006, some of its members are still undertaking criminal activities and have formed the so called bandas criminales. These three groups are involved in drug production and trafficking operations, which are known to be the main financing source of the Colombian armed groups. They do not engage only in a direct fighting with the national army, but also perpetrate crimes against the civilian population, private assets and public infrastructure. They have committed several attacks in most of the country's territory, affecting most of the population (Rabassa and Chalk, 2001). Thus, it is likely that the activity of these groups impoverish affected populations. Measuring the magnitude of this impact is the aim of this paper.

Poverty in South America has fallen steadily over the last decade, most likely owing to favorable economic conditions and innovative social programs such as conditional cash transfers. Colombia, while exhibiting a trend similar to that of the region, shows less encouraging results. In 2008, according to World Bank, Colombia was the second country in the region with the highest percentage of people below the poverty line (measured as US\$1.25 per day), after Bolivia. Again, armed conflict in Colombia may explain to some extent the underperformance of the country relative to its neighbors.

As mentioned before, this study measures poverty with the MPI, an index based on the methodology of Alkire and Foster (2010). The proposed index for Colombia is composed of 15 indicators grouped by five dimensions: household education conditions; childhood and youth conditions; health; employment; and households' living conditions and access to utilities (see Table 8 in the appendix). A person is considered poor if he has 33\% of deprivations. A nested 
weighting structure is used to compute the index for each household, where each dimension is equally weighted, as is each indicator within each dimension. ${ }^{3}$

Alkire, Roche, Santos and Seth (2011a) state that a key advantage of the MPI is that it is able to 'zoom in' and explore the incidence, intensity and depth of poverty by states, provinces or other geographical regions, capturing reductions in the number of people who are poor as well as in the intensity of poverty. Moreover, the MPI is the first international measure to reflect the intensity of poverty - the number of deprivations that each person faces at the same time. In this way, the MPI goes beyond other poverty measures to reveal the combination of deprivations that batter a person at the same time, which has been designed as a tool to help eradicate poverty.

A multidimensional poverty measure should capture welfare losses that result when poor households face greater deprivations. As Angulo, Diaz and Pardo (2013) indicate, The Unsatisfied Basic Needs (UBN) measure, one of the multidimensional indices traditionally used in Colombia, does not change if a poor household increases its number of deprivations. Also, a poverty measure should only reflect improvements among the universe of poor people, a property that the Living Conditions Index $(\mathrm{LCl})$, another traditional multidimensional index used in Colombia, fails to fulfill as it is sensitive to changes in the living conditions of the non-poor. On the other hand, there are problems with the content of these indices as well, so they are arguably becoming poor instruments for measuring poverty. Because of this, the measure that I use in this study is the MPI, which looks at poverty through a 'high-resolution' lens, including variables that had not been included in previous multidimensional indices and satisfying a set of axiomatic properties that allows for the definition of consistent profiles of multidimensional poverty. ${ }^{4}$

The negative consequences of civil conflict on economic activity and human wellbeing have been widely studied. The outcomes studied include economic growth, income, wealth, poverty, education, health and the environment, among others (see Vargas, 2012 for a review). Most of the existing literature has focused on cross-country evidence at the aggregate level. Collier (1999) estimates that countries that experience civil conflict grow approximately 2.2 less percentage points than peaceful countries. Stewart et al. (2001) find that fifteen out of sixteen countries that have experienced an internal conflict suffered a decrease in their GDP per capita. This evidence,

\footnotetext{
${ }^{3}$ Thus far, MPI in Colombia can only be measured, at the municipality level, using the 2005 Census. This limits the sample period of the present study. Indeed, the previous Census, carried out in 1993, does not have enough information to capture the MPI. See Section 3 for details.

${ }^{4}$ See appendix for methodological details on MPI and a discussion of its virtues and limitations, as well as a comparison with other indices traditionally used in Colombia.
} 
although suggestive, may suffer from limitations such as measurement error, omitted variable bias and reverse causality. Indeed, the other direction of causality on conflict and income/poverty has also been studied at the cross-country level, but this branch of the literature also suffers from identification problems (e.g. Fearon and Laitin, 2003; and Collier and Hoeffler, 2004). ${ }^{5}$

At the subnational level, the first studies that estimate the economic costs of conflict in Colombia are Rubio (1995) and Trujillo and Badel (1997). Using accounting techniques to compute such costs, both studies conclude that the total costs of armed conflict and illegal activities in the country amount to around 15\% of GDP. The social and economic costs of conflict in Colombia have also been studied by Fernandez, Ibáñez and Peña (2011), and Arias, Ibáñez and Zambrano (2013). Both studies show that households adapt to conflict in different ways, for instance by shifting labor supply to non-agricultural activities and taking other sub-optimal agricultural decisions. ${ }^{6}$ The other direction of causality (economic conditions to conflict) has also been studied in Colombia, see for example Montenegro and Posada (1995), and Becerra and Sarmiento (1999). ${ }^{7}$

Even though previous research has studied the relationship between poverty and conflict, there are several contributions of the present study. While most of the previous literature has used a cross-country approach, I exploit subnational variation within a single country (Colombia), which helps me overcome identification concerns. Moreover, while the cross-country literature focuses on GDP per capita as the main proxy for poverty, I use a newly developed comprehensive poverty measure.

The rest of the paper is organized as follows. Section 2 presents the empirical strategy. Section 3 describes the data. Section 4 presents the main results and robustness checks and finally section 5 concludes.

\section{Empirical Strategy}

In this paper, I use an Instrumental Variables (IV) approach. This approach not only addresses the potential reverse causality, but also reduces any possible bias due to (classical) measurement error or omitted variables. An instrument in this specific case is an exogenous

\footnotetext{
${ }^{5}$ One exception is Miguel et al. (2004), who use annual rainfall growth as an instrument for income growth in Sub-Saharan Africa.

${ }^{6}$ Other important references on the economic and social costs of conflict in Colombia include the already mentioned studies of Camacho and Rodríguez (2011), and Rodríguez and Sánchez (2012). For the long-run economic consequences see Camacho (2008).

${ }^{7}$ Dube and Vargas (2013) estimate the causal effect of negative income shock on conflict using exogenous changes in the interantional price of commodities intensively produced in Colombia.
} 
source of variation for conflict that otherwise is unrelated to poverty. Illegal drug laboratories dismantled and weapons seized are good candidates because they reflect government deterrence (actions that are typically carried out by the military), while at the same time are unlikely to have a direct impact on poverty. ${ }^{8}$

The model that I will estimate is based on a two stages least squares approach. In the first stage, the endogenous variable of interest (Conflict) is regressed against the instrument (a vector of government deterrence measures, Deterrence) and a rich set of municipality-level controls $(X){ }^{9}$ All these variables vary across municipalities $(m)$, and time $(t)$. However, because the dependent variable is only available for one year (2005), my estimation only exploits the cross sectional variation. In turn, I do explore the effect of different lags of the independent variables to assess the duration of the effect.

The estimated model is given by:

$$
\text { Conflict }_{m}=\alpha+\beta_{1} \text { Deterrence }_{m}+\beta_{2} X_{m}+\epsilon_{m}
$$

In turn, the second stage can be described by:

$$
\text { Poverty }_{m\{2005\}}=\delta+\theta_{1} \text { Conflict }_{m\{2005,2004,2003,2002\}}+\theta_{2} X_{m}+\mu_{m}
$$

where the outcome (poverty as measured by the MPI) is explained by the predicted value of the endogenous variable of interest from the first stage. ${ }^{10}$

The deterrence actions should be significantly correlated with armed conflict in the first equation, given that they proxy for both the presence and the effectiveness of the government to

\footnotetext{
${ }^{8}$ I focus on the number of illegal drug laboratories dismantled and weapons seized because including captures of assassins (Rodríguez and Sánchez, 2012), being this a significantly different measure from a conceptual point, makes the assumption of the Sargan Test less likely to hold. On the other hand, antinarcotic operations (Camacho and Rodríguez, 2011) have many zeros and given that I do not have a panel but a cross-section, it does not give me enough variation in the first stage to estimate its effect on conflict.

${ }^{9}$ The municipality-level controls include geographical variables; education variables; institutional variables; financial variables; and royalties. Population is included as a scale control. Land inequality is also included as a control, but only in robustness tables because it excludes all the municipalities of Antioquia, since its department has its own cadastral records which are not public.

10 The year indices in the second equation indicate when are the variables measured. This notation differentiates between the contemporaneous and lagged estimations.
} 
counteract criminal activity in a specific region. Indeed, all Colombian armed groups use drug production and distribution as a major financing source, as well as a large variety of weapons to carry out their operations. Hence, higher values of laboratories dismantled and weapons seized are likely to proxy for higher presence of government forces and in turn, this is likely to hinder illegal activities, including the actions of illegal armed groups. Therefore, one would a priori expect a negative association between the deterrence measures and armed conflict. However, the opposite sign should not be ruled out since one can also expect illegal armed groups try to protect their sources of finance (e.g. laboratories), or force (e.g. weaponry and ammunition) through armed attacks. ${ }^{11}$ Critically, the only channel through which the deterrence actions are likely to affect poverty is through conflict, which means that the exclusion restriction is met. Indeed, deterrence actions are normally secret operations that occur in environments not easily detected by the civilian population, and households do not easily observe the level of deterrence. It follows that government deterrence operations are unlikely to directly affect poverty.

It is worth noting however that the effect of conflict on poverty is not necessarily immediate. Contemporaneous poverty may not only be explained by conflict in 2005 but also by past levels of this variable. I then explore a flexible lag structure of conflict (as well as the instruments) in my empirical exercise.

\section{Data}

To examine econometrically the connection between armed conflict and poverty, I use data on both on the incidence of conflict and on poverty rates. In terms of the latter, I use the Censusbased MPI poverty measure (2005). This is computed at the municipality level and, within each municipality, the aggregate rate can be divided into urban and rural rates. One caveat to be noticed is that, because it is based on census data, my outcome variable is only measured in one cross section. Indeed, it is impossible to compute the MPI based on the 1993 Census. ${ }^{12}$

\footnotetext{
${ }^{11}$ Camacho and Rodríguez (2011) find such positive relationship in the first stage of their instrumental variables specification. The hypothesis that armed groups try to protect their sources of finance violently is consistent with the results of Idrobo et al. (2013), and Abadie et al. (2013).

12 There are four main variables for the MPI that are not included in the 1993 Census: i) access to childcare services, ii) affiliation to a pension fund (proxy of formality), iii) health insurance coverage, and iv) access to health services in case of need. Upon examination, it turns out that these variables can not be extrapolated using contemporaneous households surveys (ENDS 1995 and ECV 1993). Indeed, the National Planning Department of Colombia (DNP) has also concluded that the MPI can not be calculated with the 1993 Census (personal communication with Roberto Angulo and Renata Pardo).
} 
Since it can be argued that access to health insurance (one of the variables used to compute the MPI) doesn't monotonically map to poverty and living conditions, for robustness I re-calculate an MPI-equivalent index that excludes such variable. ${ }^{13}$ As I will show, my results are robust to this.

For the conflict data I use a detailed event-based data from the Center for the Study for Armed Conflict (CERAC), updated by Universidad del Rosario. For every event the conflict dataset records its type, the date, location, perpetrator, and victims involved in the incident. The dataset is described thoroughly by Restrepo, Spagat, and Vargas (2004). From this dataset I use the following variables: guerrilla attacks, paramilitary attacks, attacks from unknown groups and the number of conflict-driven casualties. An attack is defined as a violent event in which there is no direct armed combat between two groups. Attacks include explosive terrorist attacks, arsonist terrorist attacks, other terrorist attacks, route blocking, harassing and ambushes, among others. Casualties, which are the number of people killed, is a conflict intensity measure. As mentioned before, I take into account the potential lagged effect of conflict on poverty. Thus, my conflict data covers the period 2002 to 2005.

In addition, the instruments (illegal drug laboratories dismantled and weapons seized) are taken from a database from the Center of the Studies for Economic Development (CEDE). I also take these variables for the period 2002-2005.

Table 1 reports the descriptive statistics of the poverty measure, the incidence of conflict and the instruments. Poverty is higher in rural than in urban areas: in 2005, $80 \%$ of the population in rural areas lived in poverty, while only $39 \%$ in urban areas did. Note that while in some areas as little as $14 \%$ of the population lived in poverty is 2005 , in some others the entire population was classified as poor. In terms of the incidence of conflict, on average a municipality in 2005 has 0.2 (guerrilla and paramilitary) attacks, 0.27 attacks from unknown groups, and 1.34 conflict-driven casualties. Finally, the deterrence measures exhibit a similar behavior on average: 0.22 laboratories dismantled and 0.37 weapons seized.

\section{Results}

\subsection{Baseline Results}

Using the IV approach described in section 2, I estimate the contemporaneous and lagged effect of conflict on poverty. Tables $2 \mathrm{~A}$ through 2D examine respectively the effect of guerrilla

\footnotetext{
${ }^{13}$ I am greateful to Adriana Camacho for this suggestion.
} 
attacks, paramilitary attacks, unknown attacks, and conflict-driven casualties on poverty. In addition, each table is divided into two panels and four columns. Panel A reports the first stage and Panel B reports the second. The columns report the contemporaneous and lagged effects up to the third lag (when the effect disappears).

Focusing on the first stage, the relationship between the instruments and the incidence of conflict is typically positive. This is consistent with the hypothesis, already mentioned, that government deterrence actions are challenged by the illegal groups. While in some cases either the laboratories dismantled or the weapons seized (but very rarely both of them together) are not significant, it is noteworthy that the instruments are generally relevant. One exception is the contemporaneous effect of paramilitary attacks (Table 2B, Panel A). This is consistent with the fact that the AUC reached its peak of expansion in 2002, declaring in December that year a unilateral cease fire which let to peace negotiations in 2003 with the government of president Uribe (2002-2010). In fact, by 2005 the large majority of the former paramilitary forces had already demobilized.

Panel A of the tables reports as well the F-Test of excluded instruments. The null hypothesis of this test is generally rejected, ensuring that under this specification my estimations do not suffer from a weak instruments problem. Again, an exception is the contemporaneous effect of the paramilitary attacks, for the reasons mentioned.

Focusing on the second stage, all of my proxies of armed conflict have a positive effect on rural and urban poverty, but this effect is only significant for rural areas. This is intuitive as most of the conflict takes place in rural zones. Something interesting to be noted from the lagged specification is that the effect of conflict on rural poverty becomes smaller over time. A possible explanation for this is that households get used to live in the presence of conflict (when they live in regions with prolonged illegal armed groups' presence). This is consistent with the interpretation of Fernandez et al. (2011) and Arias et al. (2013). The positive and significant effect on rural poverty remains up to the second lag window in 2003. It is no longer significant starting in 2002 (results of longer lags not presented).

Because all the conflict-specific variables are standardized, coefficients should be interpreted as the impact (in percentage points of poverty) of one additional standard deviation of each conflict variable. The contemporaneous effect of one standard deviation increase in guerrilla attacks (Table 2A, column 1 ) is an increase on rural poverty of 3.7 percentage points. A one standard deviation increase in the first and second lag of guerrilla attacks (columns 2 and 3 ) 
increase rural poverty by 1.9 and 1.6 percentage points respectively. Starting from the third lag (column 4), the effect is no longer significant.

Turning to the effect of paramilitary attacks on poverty (Table 2B), the only significant effects are given by the first and second lag of paramilitary attacks (columns 2 and 3). A one standard deviation increase in these, increase rural poverty by 3.4 and 3 percentage points respectively. The effect of attacks from unknown groups (Table $2 \mathrm{C}$ ) is somewhat larger; with the contemporaneous effect of one standard deviation increase (column 1) being 6.5 percentage points increase on rural poverty. This effect drops to 2.9 percentage points increase by the third lag (column 4).

Finally, the contemporaneous effect of one additional standard deviation of conflict-related casualties (Table 2D, column 1 ) is an increase on rural poverty of 3.7 percentage points. The smallest effect of casualties, observed in the second lag (2003), is an increase on rural poverty of 1.5 percentage points (column 3 ).

Across all tables Panel B reports as well the Sargan Test to assess the exogeneity of my instruments. None of the Sargan Tests from my different lag windows rejects the null hypothesis that, assuming that one of the instruments is exogenous, the second one is also exogenous.

Given the inclusion of a large set of controls, some of which are missing for some municipalities, the resulting sample in my estimations is 908 out of the 1123 municipalities. This sample loss was studied carefully to think of any potential selection problem. Table 3 suggests that while I'm losing poorer municipalities (according to both the MPI and the UBN), the municipalities lost are slightly less violent. However, a t-test for differences in means (reported in Table 3) suggests that these differences are not statistically significant in any of the conflict measures across used and the lost samples. Because I am losing municipalities that are poorer but not significantly different in terms of the incidence of conflict, if anything my results underestimate the effect of conflict on poverty.

\subsection{Robustness}

I assess the robustness of my results in different ways. First, given that one of the components of the MPI is the access to health insurance and that the proportion of insured households is likely to have a U-form with respect to living conditions (the poor and the rich are generally affiliated, while the non-poor and the non-rich are not), I construct a synthetic MPI 
excluding this variable. ${ }^{14}$ The results, summarized in Table 4 , are largely similar to the benchmark results already explained in section $4.1 .^{15}$ The effect of a one standard deviation increase in guerrilla attacks, paramilitary attacks and conflict-related casualties on rural poverty is smaller than the obtained in the benchmark results. Unlike the benchmark results, attacks from unknown groups have no effect on rural poverty. Furthermore, in this case the duration of the effect seems to be smaller: Starting from the second lag (2003), the effect of the four conflict measures is no longer significant.

In addition, given the availability of different conflict databases, in Tables 5A through 5D, the conflict-related variables are taken from the CEDE conflict database. Once more, the first stage reports a typically positive relationship between the instruments and the incidence of conflict. Indeed, the instruments are relevant (including the contemporaneous effect of paramilitary attacks, a difference with the benchmark results). The effect of conflict on rural poverty is positive and significant, and to some extent smaller than the obtained with the CERAC/URosario database (one exception is the contemporaneous effect of casualties on rural poverty [Table 5D], being bigger under the CEDE database). Generally, the interpretation is the same as in the baseline results.

Another robustness check includes in the set of controls land inequality. It is important to say that these data exclude all the 125 municipalities of Antioquia, which has its own cadaster that is not public. Something to be noted is that the laboratories dismantled and the weapons seized together are not significant in the contemporaneous and first lag effect of paramilitary attacks and unknown attacks (Tables 6B and 6C). In turn, these two variables have no effect on rural poverty for those estimations. In addition, the effect of guerrilla attacks (Table 6A) and conflict-driven casualties (Table 6D) on poverty is slightly smaller than in the baseline results. This effect is no longer significant in the second lag (2003). This is likely to be a consequence of the sample loss.

Finally, because my dependent variable is census-based, I exclude from the sample municipalities with high census omission. According to the National Administrative Department of Statistics (DANE), high census omission is defined as a municipality in which more than the $20 \%$ of

\footnotetext{
${ }^{14}$ However, what matters in a multidimensional poverty concept, like the MPI, is the simultaneous deprivations that a household faces. That is, the multidimensionally poor people need not resemble the income poor people. Moreover, the MPI excludes any change in the living conditions of the non-poor (changes whose magnitude is so that does not make them poor). A more detailed explanation may be seen in the appendix.

${ }^{15}$ The first stage is not reported in Table 4 because it is equivalent to the first stage of Tables $2 \mathrm{~A}$ through to 2D.
} 
the population was not censed; and one should treat them with caution. The results, summarized in Tables 7A through 7D, resemble the baseline first and second stage estimations, as well as the baseline magnitude and duration of the effect.

\section{Conclusions}

The aim of this paper is to assess the impact of conflict on poverty in Colombia. Most of the empirical literature focuses on the opposite direction of causality, namely the effect of poverty on conflict. Moreover, most of the previous studies proxy poverty by GDP per capita (or analyze income shocks), instead I use a newly developed, official poverty measure. Finally, I deal with potential reverse causality; omitted variable bias and measurement error using an IV approach.

I instrument conflict with the number of laboratories dismantled and the number of weapons seized, all of which are government deterrence measures. These instruments are significantly correlated with armed conflict given that they proxy for both the presence and effectiveness of the government to counteract criminal activity in the region. Instead, the government deterrence operations are unlikely to directly affect poverty, since they are secret operations that occur in environments not easily detected by the civilian population.

The findings provide evidence that the conflict has a positive and significant effect on rural poverty, but not in urban areas. This is intuitive as most of the conflict is perpetrated in rural areas. Moreover, I explore different lag windows of conflict incidence to assess the duration of the effect of conflict on poverty. The effect of conflict on poverty becomes smaller over time (with the effect disappearing after the third lag). This could be due to the fact that households may get used to live in the presence of conflict, and is consistent with recent research of the effect of conflict on household behavior in Colombia. In addition, paramilitary attacks are not related to the government deterrence actions in 2005. These results are consistent with the fact that in this year many of the paramilitary forces had already demobilized.

The results are robust to different robustness specifications. These includes: the estimation with a synthetic MPI (without access to health services), the use of a different conflict database (CEDE), the inclusion of land inequality as a control, and the exclusion from the sample of municipalities with high census omission.

It is crucial to continue examining the relationship between conflict and poverty, for instance by exploiting in the future (when other census are carried out) panel data that allows to 
control for unobserved municipal-specific heterogeneity which is time-invariant by including fixed effects.

Finally, the results of this study provide additional evidence that the gains from peace are potentially very large and that the Colombian government should determinedly commit to bring the current peace negotiations with the FARC to a successful and lasting agreement.

\section{References}

Abadie, A., Acevedo, M.C., Kugler, M., \& Vargas, J.F. (2013). Inside the War on Drugs: Effectiveness and Unintended Consequences of a Large Illicit Crops Eradication Program in Colombia. Manuscript.

Alkire, S. \& Foster, J. (2011a). Counting and Multidimensional Poverty Measurement. Journal of Public Economics, August 2011.

Alkire, S., Roche, J.M., Santos, M.E., \& Seth, S. (2011a). Multidimensional Poverty Index 011: Brief Methodological Note. OPHI Website.

Angulo, R.C., Diaz, B.Y., \& Pardo, R. (2013). Multidimensional Poverty in Colombia, 19972010. (ISER Working Paper Series No. 2013-03). Institute for Social and Economic Research, University of Essex.

Arias, M. A., Ibáñez, A. M., \& Zambrano, A. (2013). Agricultural Production amidst Conflict: The Effects of Shocks, Uncertainty and Governance of Non-State Armed Actors. (Working paper, Universidad de los Andes).

Becerra, L. M., \& Sarmiento, A. (1999). Análisis de las Relaciones entre Violencia y Equidad. Indicadores de Coyuntura Económica. Departamento Nacional de Planeación.

Becker, G. (1968). Crime and Punishment: An Economic Approach. Journal of Political Economy, Vol. 76: 169-217.

Camacho, A. (2008). Stress and Birth Weight: Evidence from Terrorist Attacks. American Economic Review, 98(2): 511-15.

Camacho, A., \& Rodríguez, C. (2011). Firm Exit and Armed Conflict in Colombia. (Working paper, Universidad de los Andes).

Collier, P. (1999). On the Economic Consequences of Civil War. Oxford Economic Papers, Vol. 51(1): 168183

Collier, P., \& Hoeffler, A. (2004). Greed and Grievance in Civil War. Oxford Economic Papers, 56(4), 563-595. 
Dube, O., \& Vargas, J. F. (2013). Commodity Price Shocks and Civil Conflict: Evidence from Colombia. Forthcoming The Review of Economic Studies.

Fearon, J. D., \& Laitin, D. D. (2003). Ethnicity, Insurgency, and Civil War. The American Political Science Review, 97(1), pp. 75-90.

Fernandez, M., Ibáñez, A. M. \& Peña, X. (2011). Adjusting the Labor Supply to Mitigate Violent Shocks: Evidence from Rural Colombia. (World Bank Working paper Series 5684).

Idrobo, N., Mejía, D., \& Tribin, A.M. (2013). Illegal Mining and Violence in Colombia. Manuscript.

Miguel, E., Satyanath, S., \& Sergenti, E. (2004). Economic Shocks and Civil Conflict: An Instrumental Variables Approach. Journal of Political Economy, 112(4), 725-753.

Montenegro, A., \& Posada, C. E. (1995). Criminalidad en Colombia. Coyuntura Económica. Fedesarrollo, Volume XXV, No.1, 81-100.

Rabassa, A. \& Chalk, P. (2001). Colombian Labyrinth: The Synergy of Drugs and Insurgency and Its Implications for Regional Stability. Rand Corporation.

Restrepo, J., Spagat, M., \& Vargas, J. F. (2004). The Dynamics of the Colombian Civil Conflict: A New Data Set. Homo Oeconomicus, 21, 396-429.

Rodríguez, C., \& Sánchez, F. (2012). Armed Conflict Exposure, Human Capital Investments and Child Labor: Evidence from Colombia. Defense and Peace Economics, 23(2), 161-184.

Rubio, M. (1995). Crimen y Crecimiento en Colombia. Coyuntura Económica. Volume XXV, No.1 March.

Stewart, F., Huang, C., \& Wang, M. (2001). Internal Wars: An Empirical Overview of the Economic and Social Consequences, War and Underdevelopment. The Economic and Social Consequences of Conflict. Volume I: Oxford University Press.

Trujillo, E., \& Badel, M. (1997). Los Costos Económicos de la Criminalidad y la Violencia en Colombia: 1991-1996. Archivos de Macroeconomía. Document No.76 March. Bogotá: Departamento Nacional de Planeación.

Vargas, Juan F. (2012). Costos del Conflicto y Consideraciones Económicas para la Construcción de Paz. Rettberg, A. (Ed.) Construcción de Paz en Colombia, Ediciones Uniandes, Bogotá: 239-272.

World Bank (2003). Breaking the Conflict Trap: Civil War and Development Policy. World Bank Policy Research Report.

World Bank. Poverty Headcount Ratio at \$1.25 a day (PPP) (\% of population). Website data. 


\begin{tabular}{lcccccc}
\hline & \multicolumn{7}{c}{ Table 1: Descriptive Statistics } & & \\
\hline \hline & Mean & Std. Dev. & Min & Max & Obs & Source \\
\hline MPI & $48.96 \%$ & 16.38 & $14.27 \%$ & $100 \%$ & 1113 & 2005 Census \\
Urban MPI & $39.09 \%$ & 18.45 & $13.23 \%$ & $100 \%$ & 1097 & 2005 Census \\
Rural MPI & $80.08 \%$ & 13.54 & $22.98 \%$ & $100 \%$ & 1095 & 2005 Census \\
\hline Guerrilla Attacks & 0.20 & 0.71 & 0 & 7 & 1123 & CERAC/Urosario \\
Paramilitary Attacks & 0.20 & 0.92 & 0 & 15 & 1123 & CERAC/Urosario \\
Unknown Attacks & 0.27 & 0.94 & 0 & 16 & 1123 & CERAC/Urosario \\
Casualties & 1.34 & 4.60 & 0 & 86 & 1123 & CERAC/Urosario \\
\hline Laboratories Dismantled & 0.22 & 0.73 & 0 & 6 & 1123 & CEDE \\
Weapons Seized & 0.37 & 1.09 & 0 & 16 & 1123 & CEDE \\
\hline
\end{tabular}

Table 2A: Baseline Results.

Contemporaneous and Lagged Effect of Guerrilla Attacks on Poverty

\begin{tabular}{lcccc}
\hline \hline & Contemporaneous & One-Year Lag & Two-Years Lag & Three-Years Lag \\
PanelA: First Stage & & & & \\
Laboratories Dismantled & $0.216^{* *}$ & $0.450^{* * *}$ & $0.146^{* * *}$ & 0.0634 \\
& $(0.0874)$ & $(0.150)$ & $(0.0526)$ & $(0.0592)$ \\
Weapons Seized & 0.0899 & 0.105 & $0.0967^{* *}$ & $0.171^{* *}$ \\
& $(0.0777)$ & $(0.0919)$ & $(0.0420)$ & $(0.0814)$ \\
R-squared & 0.162 & 0.223 & 0.267 & 0.230 \\
F-excluded Instruments & 3.73 & 6.52 & 9.99 & 2.85 \\
P-Value & 0.0243 & 0.0015 & 0.0001 & 0.0583 \\
& & & & \\
\hline PanelB: Second Stage & & & & 0.0137 \\
Urban MPI & 0.0120 & 0.00819 & 0.00466 & $(0.0135)$ \\
& $(0.0182)$ & $(0.00988)$ & $(0.00956)$ & 0.487 \\
R-squared & 0.493 & 0.490 & 0.488 & 0.603 \\
Sargan Test: Chi-sq(1) & 1.345 & 1.125 & 0.000 & 0.4373 \\
P-Value & 0.2462 & 0.2887 & 0.9892 & 0.0289 \\
Rural MPI & $0.0366^{* *}$ & $0.0192^{* * *}$ & $0.0160^{*}$ & $(0.0177)$ \\
& $(0.0148)$ & $(0.00726)$ & $(0.00825)$ & 0.382 \\
R-squared & 0.383 & 0.403 & 0.405 & 0.107 \\
Sargan Test: Chi-sq(1) & 0.530 & 1.451 & 5.757 & 0.7433 \\
P-Value & 0.4665 & 0.2284 & 0.0164 & 908 \\
Observations & 908 & 908 & 908 & \\
\hline
\end{tabular}

Robust standard errors in parentheses

*** $p<0.01, * * p<0.05, * p<0.1$ 
Table 2B: Baseline Results.

Contemporaneous and Lagged Effect of Paramilitary Attacks on Poverty

\begin{tabular}{|c|c|c|c|c|}
\hline & Contemporaneous & One-Year Lag & Two-Years Lag & Three-Years Lag \\
\hline \multicolumn{5}{|l|}{ Panel A: First Stage } \\
\hline \multirow[t]{2}{*}{ Laboratories Dismantled } & 0.00419 & 0.158 & $0.0662^{*}$ & 0.0427 \\
\hline & $(0.0486)$ & $(0.139)$ & $(0.0396)$ & $(0.0400)$ \\
\hline \multirow[t]{2}{*}{ Weapons Seized } & 0.0507 & $0.157^{*}$ & $0.112^{* *}$ & 0.109 \\
\hline & $(0.0425)$ & $(0.0950)$ & $(0.0441)$ & $(0.0742)$ \\
\hline R-squared & 0.264 & 0.169 & 0.367 & 0.298 \\
\hline F-excluded Instruments & 0.75 & 3.69 & 4.21 & 2.02 \\
\hline P-Value & 0.4742 & 0.0253 & 0.0152 & 0.1334 \\
\hline \multicolumn{5}{|l|}{ Panel B: Second Stage } \\
\hline \multirow[t]{2}{*}{ Urban MPI } & -0.0115 & 0.00569 & 0.00633 & 0.0215 \\
\hline & $(0.0541)$ & $(0.0155)$ & $(0.0150)$ & $(0.0229)$ \\
\hline R-squared & 0.482 & 0.486 & 0.483 & 0.465 \\
\hline Sargan Test: Chi-sq(1) & 1.453 & 1.646 & 0.025 & 0.557 \\
\hline P-Value & 0.2281 & 0.1995 & 0.8733 & 0.4553 \\
\hline \multirow[t]{2}{*}{ Rural MPI } & 0.131 & $0.0343^{*}$ & $0.0298^{* *}$ & 0.0442 \\
\hline & $(0.110)$ & $(0.0182)$ & $(0.0151)$ & $(0.0311)$ \\
\hline R-squared & 0.327 & 0.349 & 0.357 & 0.316 \\
\hline Sargan Test: Chi-sq(1) & 0.537 & 0.002 & 1.768 & 0.112 \\
\hline P-Value & 0.4638 & 0.9650 & 0.1836 & 0.7381 \\
\hline Observations & 908 & 908 & 908 & 908 \\
\hline \multicolumn{5}{|c|}{ Robust standard errors in parentheses } \\
\hline & $* * * p<0.01, *$ & ${ }^{*} * p<0.05, * p<0$ & & \\
\hline
\end{tabular}

Table 2C: Baseline Results.

Contemporaneous and Lagged Effect of Unknown Attacks on Poverty

\begin{tabular}{lcccc}
\hline \hline & Contemporaneous & One-Year Lag & Two-Years Lag & Three-Years Lag \\
Panel A: First Stage & & & & \\
Laboratories Dismantled & $0.123^{* *}$ & 0.0556 & 0.0527 & $0.0826^{* * *}$ \\
& $(0.0524)$ & $(0.0561)$ & $(0.0378)$ & $(0.0255)$ \\
Weapons Seized & -0.00784 & 0.0677 & $0.0749^{*}$ & 0.0331 \\
& $(0.0274)$ & $(0.0529)$ & $(0.0406)$ & $(0.0389)$ \\
R-squared & 0.227 & 0.414 & 0.547 & 0.572 \\
F-excluded Instruments & 3.04 & 1.44 & 3.82 & 5.24 \\
P-Value & 0.0484 & 0.2381 & 0.0222 & 0.0055 \\
& & & & \\
\hline Panel B: SecondStage & & & & \\
Urban MPI & 0.0473 & 0.0108 & 0.00898 & 0.0236 \\
& $(0.0409)$ & $(0.0382)$ & $(0.0199)$ & $(0.0254)$ \\
R-squared & 0.450 & 0.483 & 0.484 & 0.480 \\
Sargan Test: Chi-sq(1) & 0.429 & 1.613 & 0.018 & 0.005 \\
P-Value & 0.5126 & 0.2041 & 0.8946 & 0.9465 \\
Rural MPI & $0.0651^{* *}$ & 0.0847 & $0.0401^{* *}$ & $0.0287^{*}$ \\
& $(0.0331)$ & $(0.0520)$ & $(0.0203)$ & $(0.0166)$ \\
R-squared & 0.256 & 0.137 & 0.356 & 0.380 \\
Sargan Test: Chi-sq(1) & 4.281 & 0.034 & 2.082 & 1.184 \\
P-Value & 0.0385 & 0.8533 & 0.1491 & 0.2766 \\
Observations & 908 & 908 & 908 & 908 \\
\hline
\end{tabular}

Robust standard errors in parentheses

${ }^{* * *} p<0.01,{ }^{* *} p<0.05, * p<0.1$ 
Table 2D: Baseline Results.

Contemporaneous and Lagged Effect of Casualties on Poverty

\begin{tabular}{lcccc}
\hline \hline & Contemporaneous & One-Year Lag & Two-Years Lag & Three-Years Lag \\
PanelA: First Stage & & & & \\
Laboratories Dismantled & $0.137^{*}$ & $0.322^{* * *}$ & $0.155^{* * *}$ & 0.0741 \\
& $(0.0716)$ & $(0.114)$ & $(0.0454)$ & $(0.0473)$ \\
Weapons Seized & 0.153 & $0.202^{* *}$ & $0.167^{* * *}$ & $0.106^{*}$ \\
& $(0.0944)$ & $(0.0782)$ & $(0.0444)$ & $(0.0549)$ \\
R-squared & 0.218 & 0.261 & 0.376 & 0.166 \\
F-excluded Instruments & 3.12 & 9.25 & 15.87 & 3.64 \\
P-Value & 0.0448 & 0.0001 & 0.0000 & 0.0267 \\
& & & & \\
\hline PanelB: Second Stage & & & & 0.0188 \\
Urban MPI & 0.00527 & 0.00537 & 0.00360 & $(0.0164)$ \\
& $(0.0166)$ & $(0.0102)$ & $(0.00748)$ & 0.474 \\
R-squared & 0.487 & 0.485 & 0.486 & 0.312 \\
Sargan Test: Chi-sq(1) & 1.658 & 1.517 & 0.009 & 0.5764 \\
P-Value & 0.1979 & 0.2181 & 0.9258 & $0.0317^{*}$ \\
Rural MPI & $0.0366^{* *}$ & $0.0215^{* *}$ & $0.0147^{* *}$ & $(0.0183)$ \\
& $(0.0176)$ & $(0.00857)$ & $(0.00704)$ & 0.365 \\
R-squared & 0.381 & 0.396 & 0.399 & 0.523 \\
Sargan Test: Chi-sq(1) & 0.032 & 0.123 & 3.645 & 0.4696 \\
P-Value & 0.8587 & 0.7261 & 0.0562 & 908 \\
Observations & 908 & 908 & 908 & \\
\hline
\end{tabular}

Robust standard errors in parentheses

*** $p<0.01, * * p<0.05, * p<0.1$

Table 3: Sample Loss Analysis

\begin{tabular}{l|cc|c}
\hline \hline \multicolumn{1}{c|}{ Variables } & \multicolumn{2}{|c|}{ Missing Estimation } & t-test: Mean Differences \\
\hline & Yes & No & P-Value \\
Mean MPI & 0.7897 & 0.6733 & 0.0000 \\
Mean UBN & 0.5757 & 0.4184 & 0.0000 \\
Mean Guerrilla Attacks & 0.1971 & 0.2021 & 0.9263 \\
Mean Paramilitary Attacks & 0.1971 & 0.2065 & 0.8936 \\
Mean Unknown Attacks & 0.2253 & 0.2758 & 0.4834 \\
Mean Casualties & 1.361 & 1.338 & 0.9475 \\
\hline
\end{tabular}




\section{A 1. Appendix (Additional tables)}

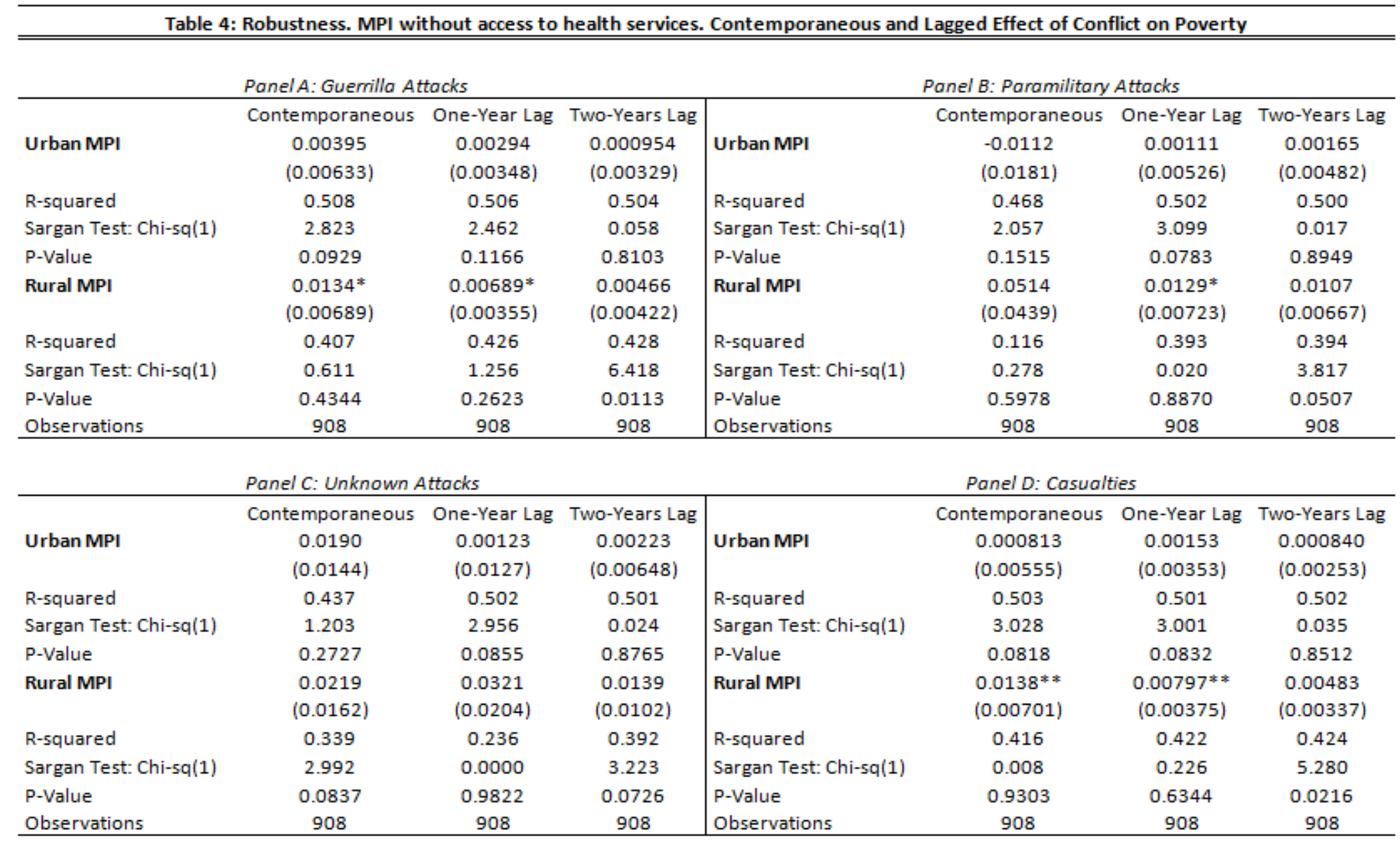

Robust standard errors in parentheses

*** $p<0.01, * * p<0.05, * p<0.1$ 


\begin{tabular}{|c|c|c|c|c|}
\hline \multicolumn{5}{|c|}{$\begin{array}{l}\text { Table 5A: Robustness. Using CEDE Database } \\
\text { Contemporaneous and Lagged Effect of Guerrilla Attacks on Poverty }\end{array}$} \\
\hline & Contemporaneous & One-Year Lag & Two-Years Lag & Three-Years Lag \\
\hline \multicolumn{5}{|l|}{ PanelA: First Stage } \\
\hline \multirow[t]{2}{*}{ Laboratories Dismantled } & $0.290 * * *$ & $0.391 * * *$ & $0.174^{* * *}$ & $0.0841^{* *}$ \\
\hline & $(0.0932)$ & $(0.0928)$ & $(0.0504)$ & $(0.0393)$ \\
\hline \multirow[t]{2}{*}{ Weapons Seized } & 0.176 & 0.202 & $0.222 * * *$ & $0.190^{*}$ \\
\hline & $(0.126)$ & $(0.129)$ & $(0.0532)$ & $(0.105)$ \\
\hline R-squared & 0.253 & 0.288 & 0.447 & 0.323 \\
\hline F-excluded Instruments & 4.88 & 9.33 & 20.41 & 5.19 \\
\hline P-Value & 0.0078 & 0.0001 & 0.0000 & 0.0057 \\
\hline \multicolumn{5}{|l|}{ Panel B: Second Stage } \\
\hline \multirow{2}{*}{ Urban MPI } & 0.00620 & 0.00545 & 0.00291 & 0.0121 \\
\hline & $(0.0118)$ & $(0.00925)$ & $(0.00619)$ & $(0.0114)$ \\
\hline R-squared & 0.488 & 0.487 & 0.486 & 0.486 \\
\hline Sargan Test: Chi-sq(1) & 1.538 & 1.490 & 0.014 & 0.513 \\
\hline P-Value & 0.2149 & 0.2222 & 0.9050 & 0.4740 \\
\hline \multirow[t]{2}{*}{ Rural MPI } & $0.0243^{* *}$ & $0.0190^{* * *}$ & $0.0125^{* *}$ & $0.0239 *$ \\
\hline & $(0.0110)$ & $(0.00717)$ & $(0.00541)$ & $(0.0130)$ \\
\hline R-squared & 0.402 & 0.405 & 0.403 & 0.399 \\
\hline Sargan Test: Chi-sq(1) & 0.154 & 0.343 & 3.637 & 0.211 \\
\hline P-Value & 0.6951 & 0.5583 & 0.0565 & 0.6459 \\
\hline Observations & 908 & 908 & 908 & 908 \\
\hline \multirow{2}{*}{\multicolumn{5}{|c|}{ Robust standard errors in parentheses }} \\
\hline & & & .1 & \\
\hline
\end{tabular}

Table 5B: Robustness. Using CEDE Database Contemporaneous and Lagged Effect of Paramilitary Attacks on Poverty

\begin{tabular}{lcccc}
\hline \hline & Contemporaneous & One-Year Lag & Two-Years Lag & Three-Years Lag \\
Panel A: First Stage & & & & \\
Laboratories Dismantled & 0.0621 & 0.0246 & 0.0333 & 0.0266 \\
& $(0.0572)$ & $(0.0499)$ & $(0.0274)$ & $(0.0204)$ \\
Weapons Seized & $0.308^{* * *}$ & $0.277^{* * *}$ & $0.164^{* * *}$ & $0.105^{* *}$ \\
& $(0.0875)$ & $(0.0890)$ & $(0.0496)$ & $(0.0408)$ \\
R-squared & 0.410 & 0.424 & 0.505 & 0.630 \\
F-excluded Instruments & 7.44 & 7.44 & 7.45 & 4.43 \\
P-Value & 0.0006 & 0.0006 & 0.0006 & 0.0121 \\
& & & & \\
\hline Panel B: SecondStage & & & & \\
Urban MPI & -0.000896 & -0.00205 & 0.00484 & 0.0221 \\
& $(0.00898)$ & $(0.0101)$ & $(0.0129)$ & $(0.0276)$ \\
R-squared & 0.486 & 0.486 & 0.484 & 0.472 \\
Sargan Test: Chi-sq(1) & 1.534 & 1.491 & 0.077 & 0.696 \\
P-Value & 0.2155 & 0.2221 & 0.7815 & 0.4040 \\
Rural MPI & $0.0215^{*}$ & $0.0240^{* *}$ & $0.0294^{* *}$ & 0.0535 \\
& $(0.0131)$ & $(0.0119)$ & $(0.0118)$ & $(0.0328)$ \\
R-squared & 0.394 & 0.387 & 0.380 & 0.339 \\
Sargan Test: Chi-sq(1) & 1.215 & 1.670 & 0.370 & 0.009 \\
P-Value & 0.2704 & 0.1963 & 0.5428 & 0.9260 \\
Observations & 908 & 908 & 908 & 908 \\
\hline & Robust standard errors in parentheses & \\
& $* * * 0<0.01, * * 0.05, * 01$ & & \\
& & & &
\end{tabular}


Table 5C: Robustness. Using CEDE Database

Contemporaneous and Lagged Effect of Unknown Attacks on Poverty

\begin{tabular}{|c|c|c|c|c|}
\hline & Contemporaneous & One-Year Lag & Two-Years Lag & Three-Years Lag \\
\hline \multicolumn{5}{|l|}{ Panel A: First Stage } \\
\hline \multirow[t]{2}{*}{ Laboratories Dismantled } & 0.0449 & $0.161^{* * *}$ & 0.0590 & 0.0258 \\
\hline & $(0.0432)$ & $(0.0599)$ & $(0.0372)$ & $(0.0197)$ \\
\hline \multirow[t]{2}{*}{ Weapons Seized } & $0.110^{*}$ & 0.0973 & $0.185^{* *}$ & 0.125 \\
\hline & $(0.0641)$ & $(0.0697)$ & $(0.0865)$ & $(0.0852)$ \\
\hline R-squared & 0.676 & 0.635 & 0.543 & 0.803 \\
\hline F-excluded Instruments & 4.64 & 4.99 & 4.96 & 2.28 \\
\hline P-Value & 0.0099 & 0.0070 & 0.0072 & 0.1024 \\
\hline \multicolumn{5}{|l|}{ Panel B: Second Stage } \\
\hline \multirow[t]{2}{*}{ Urban MPI } & 0.00145 & 0.0112 & 0.00423 & 0.0184 \\
\hline & $(0.0248)$ & $(0.0208)$ & $(0.0106)$ & $(0.0227)$ \\
\hline R-squared & 0.486 & 0.484 & 0.485 & 0.483 \\
\hline Sargan Test: Chi-sq(1) & 1.598 & 1.546 & 0.061 & 0.777 \\
\hline P-Value & 0.2062 & 0.2137 & 0.8052 & 0.3782 \\
\hline \multirow[t]{2}{*}{ Rural MPI } & $0.0585^{*}$ & $0.0437^{* *}$ & $0.0236^{* * *}$ & 0.0470 \\
\hline & $(0.0302)$ & $(0.0177)$ & $(0.00915)$ & $(0.0349)$ \\
\hline R-squared & 0.330 & 0.371 & 0.398 & 0.385 \\
\hline Sargan Test: Chi-sq(1) & 0.437 & 0.150 & 1.122 & 0.005 \\
\hline P-Value & 0.5086 & 0.6987 & 0.2895 & 0.9453 \\
\hline Observations & 908 & 908 & 908 & 908 \\
\hline
\end{tabular}

Robust standard errors in parentheses

${ }^{* * *} p<0.01,{ }^{* *} p<0.05,{ }^{*} p<0.1$

Table 5D: Robustness. Using CEDE Database

Contemporaneous and Lagged Effect of Casualties on Poverty

\begin{tabular}{|c|c|c|c|c|}
\hline & Contemporaneous & One-Year Lag & Two-Years Lag & Three-Years Lag \\
\hline \multicolumn{5}{|l|}{ Panel A: First Stage } \\
\hline \multirow[t]{2}{*}{ Laboratories Dismantled } & -0.0132 & $0.0841^{* *}$ & $0.179 * *$ & $0.125^{*}$ \\
\hline & $(0.0438)$ & $(0.0413)$ & $(0.0708)$ & $(0.0756)$ \\
\hline \multirow[t]{2}{*}{ Weapons Seized } & $0.125^{* *}$ & $0.327^{* * *}$ & $0.0967^{* * *}$ & 0.0427 \\
\hline & $(0.0532)$ & $(0.0518)$ & $(0.0304)$ & $(0.0386)$ \\
\hline R-squared & 0.105 & 0.570 & 0.588 & 0.181 \\
\hline F-excluded Instruments & 3.40 & 25.20 & 20.49 & 2.51 \\
\hline P-Value & 0.0337 & 0.0000 & 0.0000 & 0.0817 \\
\hline \multicolumn{5}{|l|}{ Panel B: Second Stage } \\
\hline \multirow[t]{2}{*}{ Urban MPI } & -0.00898 & -0.000433 & 0.00401 & 0.0158 \\
\hline & $(0.0231)$ & $(0.00850)$ & $(0.00814)$ & $(0.0125)$ \\
\hline R-squared & 0.483 & 0.486 & 0.487 & 0.481 \\
\hline Sargan Test: Chi-sq(1) & 1.368 & 1.555 & 0.000 & 0.001 \\
\hline P-Value & 0.2421 & 0.2124 & 0.9898 & 0.9700 \\
\hline \multirow[t]{2}{*}{ Rural MPI } & $0.0520^{*}$ & $0.0202^{*}$ & 0.0128 & $0.0189^{*}$ \\
\hline & $(0.0265)$ & $(0.0105)$ & $(0.00828)$ & $(0.0111)$ \\
\hline R-squared & 0.273 & 0.393 & 0.400 & 0.387 \\
\hline Sargan Test: Chi-sq(1) & 2.147 & 1.079 & 5.768 & 1.248 \\
\hline P-Value & 0.1428 & 0.2989 & 0.0163 & 0.2639 \\
\hline Observations & 908 & 908 & 908 & 908 \\
\hline
\end{tabular}

Robust standard errors in parentheses

*** $p<0.01,{ }^{* *} p<0.05,{ }^{*} p<0.1$ 
Table 6A: Robustness. Controlling for land inequality Contemporaneous and Lagged Effect of Guerrilla Attacks on Poverty

\begin{tabular}{lccc}
\hline \hline & Contemporaneous & One-Year Lag & Two-Years Lag \\
PanelA: First Stage & & & \\
Laboratories Dismantled & $0.208^{* *}$ & $0.371^{* *}$ & $0.222^{* * *}$ \\
& $(0.0970)$ & $(0.162)$ & $(0.0516)$ \\
Weapons Seized & 0.100 & 0.101 & $0.0787^{*}$ \\
& $(0.0807)$ & $(0.0920)$ & $(0.0419)$ \\
R-squared & 0.199 & 0.220 & 0.358 \\
F-excluded Instruments & 3.18 & 4.35 & 16.10 \\
P-Value & 0.0423 & 0.0133 & 0.0000 \\
& & & \\
\hline Panel B: Second Stage & & & \\
Urban MPI & 0.00704 & 0.00494 & -0.00526 \\
& $(0.0170)$ & $(0.0115)$ & $(0.00827)$ \\
R-squared & 0.519 & 0.517 & 0.510 \\
Sargan Test: Chi-sq(1) & 0.030 & 0.010 & 0.757 \\
P-Value & 0.8615 & 0.9189 & 0.3844 \\
Rural MPI & $0.0277^{* *}$ & $0.0158^{*}$ & 0.00800 \\
R-squared & $(0.0129)$ & $(0.00847)$ & $(0.00704)$ \\
Sargan Test: Chi-sq(1) & 0.433 & 0.450 & 0.452 \\
P-Value & 2.584 & 3.720 & 6.899 \\
Observations & 0.1079 & 0.0538 & 0.0086 \\
\hline
\end{tabular}

Robust standard errors in parentheses

*** $p<0.01, * * p<0.05, * p<0.1$

Table 6B: Robustness. Controlling for land inequality

Contemporaneous and Lagged Effect of Paramilitary Attacks on Poverty

\begin{tabular}{lccc}
\hline \hline & Contemporaneous & One-Year Lag & Two-Years Lag \\
Panel A: First Stage & & & \\
Laboratories Dismantled & -0.0502 & 0.142 & $0.110^{* *}$ \\
& $(0.0497)$ & $(0.150)$ & $(0.0514)$ \\
Weapons Seized & 0.0681 & 0.171 & $0.107^{* *}$ \\
& $(0.0448)$ & $(0.105)$ & $(0.0502)$ \\
R-squared & 0.237 & 0.189 & 0.214 \\
F-excluded Instruments & 1.68 & 3.01 & 3.83 \\
P-Value & 0.1870 & 0.0497 & 0.0222 \\
& & & \\
\hline Panel B: Second Stage & & & \\
Urban MPI & -0.000203 & 0.00530 & -0.00432 \\
& $(0.0432)$ & $(0.0141)$ & $(0.0129)$ \\
R-squared & 0.514 & 0.514 & 0.514 \\
Sargan Test: Chi-sq(1) & 0.186 & 0.082 & 1.107 \\
P-Value & 0.6660 & 0.7746 & 0.2927 \\
Rural MPI & 0.0905 & $0.0289^{*}$ & 0.0200 \\
& $(0.0574)$ & $(0.0158)$ & $(0.0124)$ \\
R-squared & 0.073 & 0.405 & 0.434 \\
Sargan Test: Chi-sq(1) & 1.007 & 0.463 & 5.783 \\
P-Value & 0.3155 & 0.4960 & 0.0162 \\
Observations & 769 & 769 & 769 \\
\hline
\end{tabular}

Robust standard errors in parentheses

${ }^{* * *} p<0.01,{ }^{* *} p<0.05,{ }^{*} p<0.1$ 
Table 6C: Robustness. Controlling for land inequality Contemporaneous and Lagged Effect of Unknown Attacks on Poverty

\begin{tabular}{lccc}
\hline \hline & Contemporaneous & One-Year Lag & Two-Years Lag \\
PanelA: First Stage & & & \\
Laboratories Dismantled & 0.0666 & 0.0176 & 0.0689 \\
Weapons Seized & $(0.0548)$ & $(0.0411)$ & $(0.0448)$ \\
& 0.0113 & 0.0505 & $0.102^{* *}$ \\
R-squared & $(0.0291)$ & $(0.0515)$ & $(0.0504)$ \\
F-excluded Instruments & 0.237 & 0.279 & 0.163 \\
P-Value & 1.18 & 0.63 & 4.70 \\
& 0.3078 & 0.5327 & 0.0093 \\
\hline PanelB: Second Stage & & & \\
Urban MPI & & & \\
& 0.0295 & 0.0175 & -0.00304 \\
R-squared & $(0.0662)$ & $(0.0580)$ & $(0.0173)$ \\
Sargan Test: Chi-sq(1) & 0.502 & 0.511 & 0.515 \\
P-Value & 0.002 & 0.113 & 1.257 \\
Rural MPI & 0.9635 & 0.7370 & 0.2623 \\
R-squared & 0.0839 & 0.122 & $0.0301^{*}$ \\
Sargan Test: Chi-sq(1) & $(0.0634)$ & $(0.104)$ & $(0.0182)$ \\
P-Value & 0.134 & 0.070 & 0.414 \\
Observations & 3.375 & 0.071 & 3.077 \\
\hline & 0.0662 & 0.7893 & 0.0794 \\
& 769 & 769 & 769 \\
\hline
\end{tabular}

Robust standard errors in parentheses

*** $p<0.01, * * p<0.05, * p<0.1$

\begin{tabular}{lccc}
\hline \multicolumn{4}{c}{ Table 6D: Robustness. Controlling for land inequality } \\
Contemporaneous and Lagged Effect of Casualties on Poverty \\
\hline \hline & Contemporaneous & One-Year Lag & Two-Years Lag \\
Panel A: First Stage & & & \\
Laboratories Dismantled & 0.101 & $0.236^{*}$ & $0.163^{* * *}$ \\
& $(0.0803)$ & $(0.124)$ & $(0.0577)$ \\
Weapons Seized & $0.172^{*}$ & $0.203^{* *}$ & $0.122^{* * *}$ \\
& $(0.101)$ & $(0.0798)$ & $(0.0373)$ \\
R-squared & 0.258 & 0.284 & 0.344 \\
F-excluded Instruments & 2.26 & 6.39 & 12.21 \\
P-Value & 0.1047 & 0.0018 & 0.0000 \\
& & & \\
\hline Panel B: Second Stage & & & \\
Urban MPI & 0.00531 & 0.00427 & -0.00408 \\
& $(0.0152)$ & $(0.0110)$ & $(0.00976)$ \\
R-squared & 0.516 & 0.514 & 0.513 \\
Sargan Test: Chi-sq(1) & 0.098 & 0.064 & 0.980 \\
P-Value & 0.7547 & 0.8010 & 0.3221 \\
Rural MPI & $0.0324^{* *}$ & $0.0207^{* *}$ & 0.0133 \\
R-squared & $(0.0157)$ & $(0.00921)$ & $(0.00869)$ \\
Sargan Test: Chi-sq(1) & 0.435 & 0.442 & 0.449 \\
P-Value & 0.444 & 1.099 & 5.920 \\
Observations & 0.5053 & 0.2945 & 0.0150 \\
\hline & 769 & 769 & 769 \\
\hline
\end{tabular}

Robust standard errors in parentheses

*** $p<0.01,{ }^{* *} p<0.05,{ }^{*} p<0.1$ 


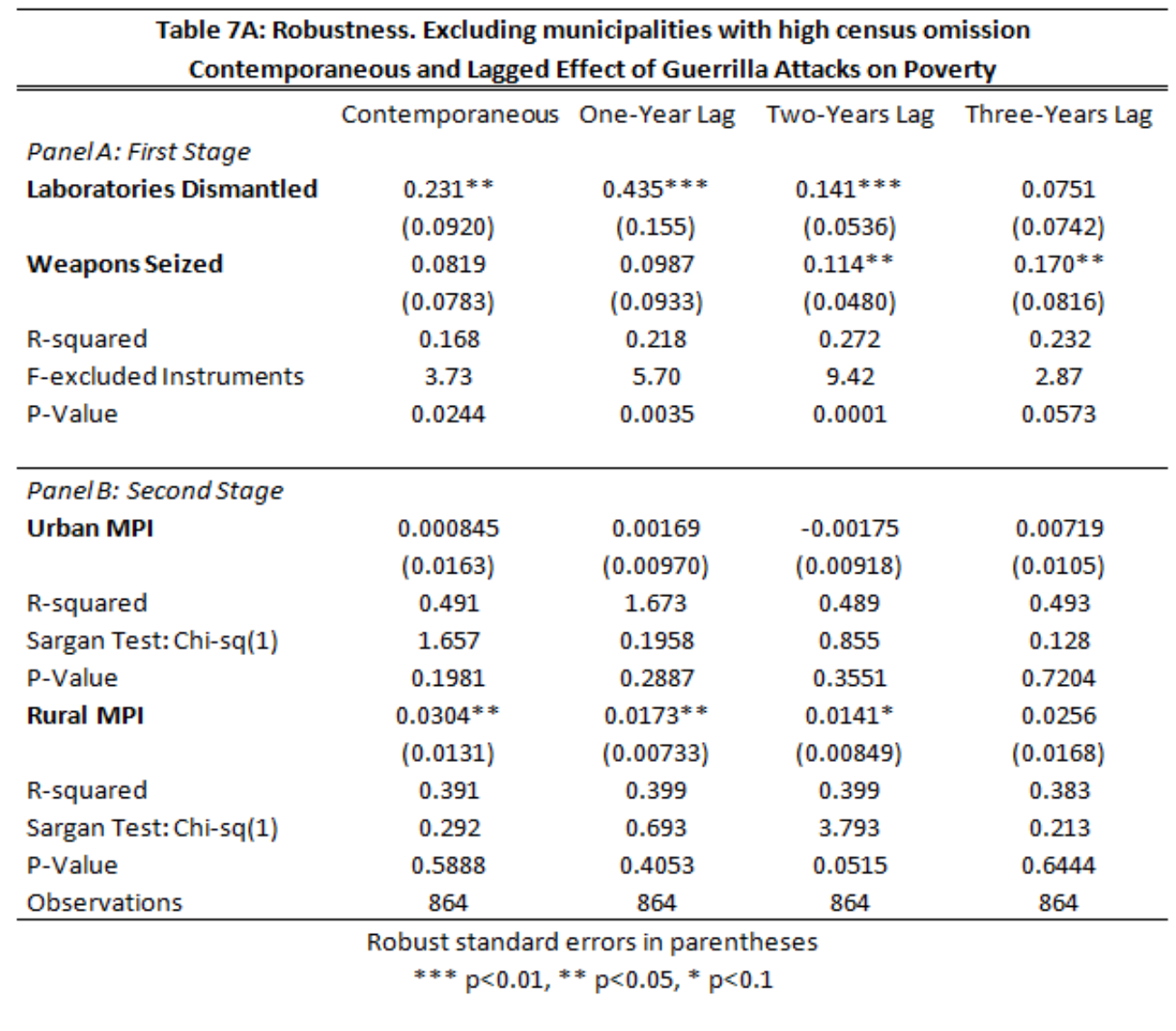

\begin{tabular}{|c|c|c|c|c|}
\hline \multicolumn{5}{|c|}{$\begin{array}{l}\text { Table 7B: Robustness. Excluding municipalities with high census omission } \\
\text { Contemporaneous and Lagged Effect of Paramilitary Attacks on Poverty }\end{array}$} \\
\hline & Contemporaneous & One-Year Lag & Two-Years Lag & Three-Years Lag \\
\hline \multicolumn{5}{|l|}{ Panel A: First Stage } \\
\hline \multirow[t]{2}{*}{ Laboratories Dismantled } & 0.00671 & 0.171 & 0.0569 & 0.0573 \\
\hline & $(0.0517)$ & $(0.145)$ & $(0.0390)$ & $(0.0529)$ \\
\hline \multirow[t]{2}{*}{ Weapons Seized } & 0.0435 & 0.146 & $0.144^{* * *}$ & 0.108 \\
\hline & $(0.0434)$ & $(0.0965)$ & $(0.0494)$ & $(0.0747)$ \\
\hline R-squared & 0.269 & 0.168 & 0.389 & 0.304 \\
\hline F-excluded Instruments & 0.54 & 3.48 & 4.73 & 2.09 \\
\hline P-Value & 0.5814 & 0.0312 & 0.0091 & 0.1244 \\
\hline \multicolumn{5}{|l|}{ Panel B: Second Stage } \\
\hline \multirow[t]{2}{*}{ Urban MPI } & -0.0516 & -0.00420 & -0.00590 & 0.0109 \\
\hline & $(0.0659)$ & $(0.0141)$ & $(0.0114)$ & $(0.0162)$ \\
\hline R-squared & 0.410 & 0.490 & 0.490 & 0.484 \\
\hline Sargan Test: Chi-sq(1) & 0.588 & 1.328 & 0.563 & 0.088 \\
\hline P-Value & 0.4431 & 0.2492 & 0.4531 & 0.7668 \\
\hline \multirow[t]{2}{*}{ Rural MPI } & 0.121 & $0.0289^{*}$ & $0.0250^{*}$ & 0.0364 \\
\hline & $(0.119)$ & $(0.0170)$ & $(0.0133)$ & $(0.0268)$ \\
\hline R-squared & 0.248 & 0.358 & 0.366 & 0.337 \\
\hline Sargan Test: Chi-sq(1) & 0.452 & 0.011 & 0.918 & 0.293 \\
\hline P-Value & 0.5013 & 0.9182 & 0.3381 & 0.5885 \\
\hline Observations & 864 & 864 & 864 & 864 \\
\hline
\end{tabular}




\begin{tabular}{|c|c|c|c|c|}
\hline \multicolumn{5}{|c|}{$\begin{array}{l}\text { Table 7C: Robustness. Excluding municipalities with high census omission } \\
\text { Contemporaneous and Lagged Effect of Unknown Attacks on Poverty }\end{array}$} \\
\hline & Contemporaneous & One-Year Lag & Two-Years Lag & Three-Years Lag \\
\hline \multicolumn{5}{|l|}{ PanelA: First Stage } \\
\hline \multirow[t]{2}{*}{ Laboratories Dismantled } & $0.116^{* *}$ & 0.0653 & 0.0479 & $0.102^{* * *}$ \\
\hline & $(0.0552)$ & $(0.0593)$ & $(0.0383)$ & $(0.0288)$ \\
\hline \multirow[t]{2}{*}{ Weapons Seized } & -0.00633 & 0.0640 & $0.0840^{*}$ & 0.0296 \\
\hline & $(0.0283)$ & $(0.0543)$ & $(0.0449)$ & $(0.0388)$ \\
\hline R-squared & 0.228 & 0.424 & 0.559 & 0.578 \\
\hline F-excluded Instruments & 2.48 & 1.450 & 3.52 & 6.25 \\
\hline P-Value & 0.0844 & 0.2359 & 0.0301 & 0.0020 \\
\hline \multicolumn{5}{|l|}{ Panel B: Second Stage } \\
\hline \multirow[t]{2}{*}{ Urban MPI } & 0.0235 & -0.0121 & -0.00733 & 0.00980 \\
\hline & $(0.0411)$ & $(0.0338)$ & $(0.0185)$ & $(0.0134)$ \\
\hline R-squared & 0.490 & 0.487 & 0.489 & 0.491 \\
\hline Sargan Test: Chi-sq(1) & 1.375 & 1.309 & 0.624 & 0.019 \\
\hline P-Value & 0.2409 & 0.2525 & 0.4297 & 0.8915 \\
\hline \multirow[t]{2}{*}{ Rural MPI } & $0.0635^{*}$ & 0.0691 & $0.0357^{*}$ & $0.0216^{*}$ \\
\hline & $(0.0358)$ & $(0.0440)$ & $(0.0203)$ & $(0.0128)$ \\
\hline R-squared & 0.254 & 0.220 & 0.360 & 0.384 \\
\hline Sargan Test: Chi-sq(1) & 2.348 & 0.040 & 1.425 & 1.208 \\
\hline P-Value & 0.1255 & 0.8414 & 0.2326 & 0.2717 \\
\hline Observations & 864 & 864 & 864 & 864 \\
\hline \multicolumn{5}{|c|}{ Robust standard errors in parentheses } \\
\hline \multicolumn{5}{|c|}{$* * * p<0.01, * * p<0.05, * p<0.1$} \\
\hline
\end{tabular}

Table 7D: Robustness. Excluding municipalities with high census omission Contemporaneous and Lagged Effect of Casualties on Poverty

\begin{tabular}{lcccc}
\hline \hline & Contemporaneous & One-Year Lag & Two-Years Lag & Three-Years Lag \\
PanelA: First Stage & & & & \\
Laboratories Dismantled & $0.140^{*}$ & $0.312^{* * *}$ & $0.152^{* * *}$ & 0.0736 \\
& $(0.0751)$ & $(0.119)$ & $(0.0459)$ & $(0.0571)$ \\
Weapons Seized & 0.151 & $0.197^{* *}$ & $0.179^{* * *}$ & $0.111^{* *}$ \\
& $(0.0962)$ & $(0.0802)$ & $(0.0508)$ & $(0.0561)$ \\
R-squared & 0.222 & 0.281 & 0.385 & 0.210 \\
F-excluded Instruments & 2.98 & 8.25 & 14.30 & 3.32 \\
P-Value & 0.0515 & 0.0003 & 0.0000 & 0.0365 \\
& & & & \\
\hline PanelB: SecondStage & & & & \\
Urban MPI & -0.00574 & -0.00166 & -0.00217 & 0.00965 \\
& $(0.0144)$ & $(0.00932)$ & $(0.00737)$ & $(0.0132)$ \\
R-squared & 0.487 & 0.490 & 0.490 & 0.488 \\
Sargan Test: Chi-sq(1) & 1.244 & 1.505 & 0.750 & 0.043 \\
P-Value & 0.2647 & 0.2199 & 0.3864 & 0.8350 \\
Rural MPI & $0.0302^{*}$ & $0.0185^{* *}$ & $0.0127^{*}$ & 0.0305 \\
& $(0.0157)$ & $(0.00845)$ & $(0.00731)$ & $(0.0201)$ \\
R-squared & 0.386 & 0.394 & 0.395 & 0.372 \\
Sargan Test:Chi-sq(1) & 0.112 & 0.009 & 2.597 & 0.472 \\
P-Value & 0.7381 & 0.9241 & 0.1070 & 0.4919 \\
Observations & 864 & 864 & 864 & 864 \\
\hline
\end{tabular}

Robust standard errors in parentheses

$$
\text { *** } p<0.01, * * p<0.05,{ }^{*} p<0.1
$$




\section{A 2. Appendix (Details on MPI)}

The Colombian government has made advances in the development and implementation of multidimensional poverty measures, moving away from unidimensional measures of poverty, mostly based on income or consumption. Some of the multidimensional indicators are the Unsatisfied Basic Needs Index (UBN), the Human Opportunities Index (HOI), the Living Conditions Index (LCI) and the index used for social expenditure targeting, SISBEN. However, none of the existing indicators satisfies a set of axiomatic properties that, according to theorists, a consistent profile of multidimensional poverty should display (Alkire et al., 2011a). For this and other reasons (discussed in Alkire and Foster, 2011a) these indices are arguably incomplete instruments for measuring the incidence of poverty.

Of these, the UBN is the only index created exclusively for poverty measurement. In contrast, both the LCI and SISBEN were developed with the aim of measuring wellbeing or quality of life, and although these concepts could proxy poverty in some circumstances this is not always the case (see Angulo, Diaz and Pardo, 2013 for a discussion).

This is the context that led the National Planning Department to adapt for Colombia the methodology of Alkire and Foster (2010) and develop the Multidimensional Poverty Index (MPI). The resulting index is composed of 15 indicators, grouped in five dimensions: household education conditions; childhood and youth conditions; health; employment; and households living conditions and access to utilities. A nested weighting structure is used, where each dimension is equally weighted, as is each indicator within each dimension. With this single measure policy makers can identify several features of the underlying poverty in a given territory: i) Its incidence (the percentage of multidimensionally poor); ii) Its intensity (the average deprivations among the poor); iii) Its depth (the average distance of the multidimensionally poor people from the non-poor threshold); iv) And its severity (the size of the gap within the poor, with a larger weight on the people who feature more deprivations).

There are four types of methods for the identification of multidimensionally poor people:

a) The unidimensional method aggregates the achievements of different dimensions into a single wellbeing variable and uses an aggregate cutoff point to identify the poor. Examples of this are the $\mathrm{LCl}$ and the SISBEN indices. One disadvantage of it is the loss of information on specific deprivations.

b) The union method considers a person to be multidimensionally poor if he or she is deprived in at least one dimension. An example is the UBN index. One limitation of it is 
that it may identify as poor people who are not, given that deprivation in one dimension may be due to reasons unrelated to poverty (like exceptional behavioral choices).

c) The intersection approach identifies a person as poor if he or she is deprived in all of the indicator dimensions. Given the strictness of this method, it would underestimate poverty by determining that almost no one is poor.

d) The dual-cutoff point approach is the one proposed by Alkire and Foster and used in computing the MPI. The first cutoff, defined separately for every dimension, determines whether a person is deprived in each dimension. The second cutoff is the share of deprivations above which a person is considered poor (which for the MPI 33\% of deprivations, although this is a convention arguably arbitrary).

One advantage of the MPI in comparison with previous multidimensional measures is that it fulfills of a number of axiomatic properties, which other measures do not fulfill. Some of these axiomatic properties that the MPI satisfies are:

a) The deprivation focus axiom. If a household, which is not deprived in a particular dimension, receives a higher score in that dimension, the indicator does not change. The $\mathrm{LCl}$ and SISBEN are sensitive to changes across both deprived and non-deprived dimensions, and therefore neither of them satisfies this axiom.

b) The poverty focus axiom. The index must reflect only improvements among the universe of poor people. A decrease in the share of deprivations of a non-poor household, which would increase its living conditions, does not change the poverty index. When the $\mathrm{LCl}$ and SISBEN averages are applied to a subgroup (as is generally the case), the measurement is sensitive to changes in the living conditions of the non-poor. In contrast, by construction the MPI censors vectors of realizations of the non-poor. In turn, this censoring allows isolating the changes in deprivations of the non-poor (but only changes whose magnitude is so that do not make them poor). This process ensures that the MPI satisfies the poverty focus axiom. In turn, the LCI and SISBEN do not satisfy this because they are synthetic indices and for using them in poverty, we should define a cutoff point after the aggregation, so that a change in the living conditions of the nonpoor affect the cardinality of the score (increasing it) and affect the poverty measure.

c) The dimensional monotonicity axiom. If a poor household faces a new deprivation that was not previously suffered, a higher level of poverty will be recorded. The NBI, LCl, and SISBEN do not satisfy this axiom and do not reflect the breadth of deprivation. 
d) The monotonicity axiom. Poverty decreases if an improvement occurs within a poor household's deprived dimension. The UBN does not fulfill this axiom, as changes in the level of any indicator do not necessarily produce changes in the aggregated score.

The MPI satisfies other axiomatic properties such as weak monotonicity, decomposability, replication invariance, symmetry, non-triviality, normalization, weak transfer, and weak rearrangement.

Although the MPI seems to be a quite good index in terms of all these properties, it arguably remains somewhat arbitrary in terms of the variables feed into its score and the weights that are assigned to each of them. For instance, the inclusion of access to health insurance can be discussed. And indeed in this study I re-calculate for robustness purposes a synthetic MPI that excludes this dimension. However, the possibility of including specific variables is limited by the availability of information on these.

On the other hand, there is no consensus on the weighting scheme that should be used. While currently the MPI in Colombia uses a weighing scheme by which each dimension receives an equal weight, as each variable within each dimension, other weighting conventions can be used. For instance, each dimension could exhibit a different weight according to the deprivation rates, but a constraint it faces is the moment in time when the weights are calculated. However, one of the limitations of the Colombian MPI is that the weight assigned to variables within dimensions that have many variables is lower in comparison to that of the variables within dimensions that have few variables. ${ }^{16}$

${ }^{16}$ The construction of the MPI is explained thoroughly by Angulo, Diaz, and Pardo (2013). 


\begin{tabular}{|c|c|c|c|c|}
\hline \multicolumn{5}{|c|}{ Table 8: Dimensions and Variables for MPI } \\
\hline Dimension & Variable & Total & Urban & Rural \\
\hline \multirow{2}{*}{$\begin{array}{l}\text { Household education } \\
\text { conditions }\end{array}$} & Educational achievement & $62.16 \%$ & $54.17 \%$ & $91.76 \%$ \\
\hline & Literacy & $18.46 \%$ & $14.01 \%$ & $36.94 \%$ \\
\hline \multirow{4}{*}{$\begin{array}{l}\text { Childhood and youth } \\
\text { conditions }\end{array}$} & School attendance & $8.86 \%$ & $6.53 \%$ & $18.16 \%$ \\
\hline & No schoollag & $27.78 \%$ & $25.15 \%$ & $39.11 \%$ \\
\hline & Access to childcare services & $15.78 \%$ & $13.20 \%$ & $27.20 \%$ \\
\hline & Children not working & $3.94 \%$ & $3.10 \%$ & $6.96 \%$ \\
\hline \multirow[t]{2}{*}{ Employment } & No one in long-term unemployment & $42.40 \%$ & $39.56 \%$ & $56.22 \%$ \\
\hline & Formal employment & $86.83 \%$ & $84.53 \%$ & $96.78 \%$ \\
\hline \multirow[t]{3}{*}{ Health } & Health insurance & $29.56 \%$ & $27.96 \%$ & $38.88 \%$ \\
\hline & Access to health services & $6.28 \%$ & $4.93 \%$ & $11.33 \%$ \\
\hline & Access to water source & $17.19 \%$ & $6.10 \%$ & $58.89 \%$ \\
\hline \multirow{4}{*}{$\begin{array}{l}\text { Access to public } \\
\text { utilities and } \\
\text { housing conditions }\end{array}$} & Adequate elimination of sewer waste & $16.97 \%$ & $11.39 \%$ & $42.85 \%$ \\
\hline & Adequate floors & $10.02 \%$ & $4.29 \%$ & $33.22 \%$ \\
\hline & Adequate external walls & $4.83 \%$ & $4.51 \%$ & $7.73 \%$ \\
\hline & No critical overcrowding & $19.53 \%$ & $19.43 \%$ & $23.94 \%$ \\
\hline
\end{tabular}

